\title{
Microglial activation contributes to cognitive impairments in rotenone-induced mouse Parkinson's disease model
}

Dongdong Zhang ${ }^{1+}$, Sheng $\mathrm{Li}^{2+}$, Liyan Hou ${ }^{1,2+}$, Lu Jing ${ }^{1}$, Zhengzheng Ruan', Bingjie Peng ${ }^{2}$, Xiaomeng Zhang ${ }^{2}$, Jau-Shyong Hong ${ }^{3}$, Jie Zhao ${ }^{2^{*}}$ and Qingshan Wang ${ }^{1,2^{*}}$ (D)

\begin{abstract}
Background: Cognitive decline occurs frequently in Parkinson's disease (PD), which greatly decreases the quality of life of patients. However, the mechanisms remain to be investigated. Neuroinflammation mediated by overactivated microglia is a common pathological feature in multiple neurological disorders, including PD. This study is designed to explore the role of microglia in cognitive deficits by using a rotenone-induced mouse PD model.

Methods: To evaluate the role of microglia in rotenone-induced cognitive deficits, PLX3397, an inhibitor of colonystimulating factor 1 receptor, and minocycline, a widely used antibiotic, were used to deplete or inactivate microglia, respectively. Cognitive performance of mice among groups was detected by Morris water maze, objective recognition, and passive avoidance tests. Neurodegeneration, synaptic loss, a-synuclein phosphorylation, glial activation, and apoptosis were determined by immunohistochemistry and Western blot or immunofluorescence staining. The gene expression of inflammatory factors and lipid peroxidation were further explored by using RT-PCR and ELISA kits, respectively.

(Continued on next page)
\end{abstract}

\footnotetext{
*Correspondence: zhaoj@dmu.edu.cn; wangq4@126.com

†Dongdong Zhang, Sheng Li and Liyan Hou contributed equally to this work.

${ }^{2}$ National-Local Joint Engineering Research Center for Drug-Research and Development (R\&D) of Neurodegenerative Diseases, Dalian Medical University, No. 9 W. Lvshun South Road, Dalian 116044, China 'School of Public Health, Dalian Medical University, Dalian 116044, China Full list of author information is available at the end of the article
}

C C The Author(s). 2021 Open Access This article is licensed under a Creative Commons Attribution 4.0 International License, which permits use, sharing, adaptation, distribution and reproduction in any medium or format, as long as you give appropriate credit to the original author(s) and the source, provide a link to the Creative Commons licence, and indicate if changes were made. The images or other third party material in this article are included in the article's Creative Commons licence, unless indicated otherwise in a credit line to the material. If material is not included in the article's Creative Commons licence and your intended use is not permitted by statutory regulation or exceeds the permitted use, you will need to obtain permission directly from the copyright holder. To view a copy of this licence, visit http://creativecommons.org/licenses/by/4.0/ The Creative Commons Public Domain Dedication waiver (http://creativecommons.org/publicdomain/zero/1.0/) applies to the data made available in this article, unless otherwise stated in a credit line to the data. 
(Continued from previous page)

Results: Rotenone dose-dependently induced cognitive deficits in mice by showing decreased performance of rotenone-treated mice in the novel objective recognition, passive avoidance, and Morris water maze compared with that of vehicle controls. Rotenone-induced cognitive decline was associated with neurodegeneration, synaptic loss, and Ser129-phosphorylation of a-synuclein and microglial activation in the hippocampal and cortical regions of mice. A time course experiment revealed that rotenone-induced microglial activation preceded neurodegeneration. Interestingly, microglial depletion by PLX3397 or inactivation by minocycline significantly reduced neuronal damage and a-synuclein pathology as well as improved cognitive performance in rotenoneinjected mice. Mechanistically, PLX3397 and minocycline attenuated rotenone-induced astroglial activation and production of cytotoxic factors in mice. Reduced lipid peroxidation was also observed in mice treated with combined PLX3397 or minocycline and rotenonee compared with rotenone alone group. Finally, microglial depletion or inactivation was found to mitigate rotenone-induced neuronal apoptosis.

Conclusions: Taken together, our findings suggested that microglial activation contributes to cognitive impairments in a rotenone-induced mouse PD model via neuroinflammation, oxidative stress, and apoptosis, providing novel insight into the immunopathogensis of cognitive deficits in PD.

Keywords: Neuroinflammation, Apoptosis, Microglial depletion, Cognitive deficits, Parkinson's disease

\section{Background}

Traditionally, Parkinson's disease (PD) is considered a movement disorder with progressive dopaminergic neurodegeneration and Lewy body formation in the substantia nigra [1]. Current evidence suggests that the pathological processes of PD extend beyond the nigrostratal system and degeneration of neuronal populations in other brain regions has also been noted [2]. Furthermore, patients with PD display not only motor deficits but also a lot of non-motor symptoms [3]. In the clinic, cognitive impairments are frequently observed in PD patients and are often inadequately treated, which gradually becomes an important determinant of life quality of patients $[4,5]$. Currently, the mechanisms of cognitive deficits in PD remain unclear.

Microglia-mediated neuroinflammation has been reported to contribute to the pathogenesis of PD [6]. In addition to nigrostriatal regions, activated microglia and accumulation of inflammatory factors are also noted in the hippocampus and cortex, two critical brain regions that may contribute to cognitive decline in PD [7]. Negative correlations between microglial activation and hippocampal volume or cerebral glucose metabolic rate within hippocampus have been observed in PD patients with dementia [8]. Furthermore, Menza et al. found higher levels of proinflammatory factors, such as interleukin-1 $\beta$ (IL-1 $\beta$ ) and tumor necrosis factor $\alpha$ (TNF $\alpha$ ) in the plasma of PD patients than that of individuals without PD [9]. A subsequent study demonstrated that increased TNF $\alpha$ and TNF receptor 1 contents in the plasma of PD patients are associated with poor cognitive test scores [9]. Similarly, in Alzheimer's disease (AD) patients, a positive correlation between microglial activation and the clinical dementia rating score has also been observed [10]. Additionally, activated microglia have been shown to induce neurotoxic reactive astroglia [11]. Neurotoxic astroglial activation is also considered to contribute to neuronal damage and subsequent cognitive impairment in animal models of neurodegeneration [12]. Consistently, blocking microglia-mediated conversion of astroglia to a neurotoxic phenotype by IL-10 or fluorocitrate alleviated LPS-induced depressive-like behavior and cognitive dysfunction in mice [13]. These results suggest that neuroinflammation mediated by microglia may contribute to cognitive decline in neurodegenerative disease.

To provide direct experimental evidence linking neuroinflammation and cognitive impairments in PD, a mouse PD model induced by rotenone was administered PLX3397 or minocycline to deplete brain microglia or inhibit microglial activation, respectively. Cognitive performance as well as neuronal loss, synaptic degeneration, and $\alpha$-synuclein Ser129-phosphorylation were determined. Then, the underlying mechanisms of how microglial activation contributes to cognitive impairments were further explored. Our results suggested that microglial activation damaged cognitive performance in rotenone-induced mouse PD model by exacerbating neuroinflammation, oxidative stress, and neuronal apoptosis.

\section{Methods \\ Reagents}

Rotenone was purchased from Sigma-Aldrich, Inc. (R8875, St. Louis, MO, USA). PLX3397 (S7818) and minocycline (S4226) were purchased from Selleck (Shanghai, China). The antibody against Neu-N was purchased from EMD Millipore (MAB377, Temecula, CA, USA). The anti-ionized calcium binding adaptor molecule-1 (Iba-1) and anti-glial fibrillary acidic protein 
(GFAP) antibodies were purchased from Wako Chemicals (019-19741, Richmond, VA, USA) and Dako (Z0334, Santa Clara, CA, USA), respectively. The antibodies against postsynaptic density protein 95 (PSD-95, ab13552), Ser129 phosphorylated (ab51253), and total $\alpha$ synuclein (ab6162) were purchased from Abcam (Cambridge, MA). In Situ Cell Death Detection Kit was purchased from KeyGEN BioTECH Corp (KGA7073, Jiangsu, China). The commercial assay kits for glutathione (GSH, S0052) and malondialdehyde (MDA, S1031S) were purchased from Beyotime Biotechnology (Shanghai, China). All other chemicals were of the highest grade commercially available.

\section{Animal treatment}

Eight-week old male C57BL/6 J mice (SPF Animal Laboratory of Dalian Medical University) were randomly assigned to control and two rotenone groups $(n=12$ in each group). Rotenone was freshly prepared every day in a solution of $0.1 \%$ DMSO (diluted with PBS) and was administered daily (i.p., 0.75 or $1.5 \mathrm{mg} / \mathrm{kg}$ bw/day) to mice for consecutive 3 weeks as described previously $[14,15]$. For the time course study, mice were treated with $1.5 \mathrm{mg} / \mathrm{kg}$ bw/day rotenone. After 1,2 , and 3 weeks of initial rotenone injection, mice $(n=4$ in each time point) were sacrificed and the brains were dissected. Mice in control group were given equal amount of $0.1 \%$ DMSO (diluted with PBS). All mice were housed under standard laboratory conditions (a 12-h light/dark cycle with an average room temperature of $25^{\circ} \mathrm{C}$ ). All animal procedures and their care were performed in strict accordance with the National Institutes of Health guidelines and were approved by the Institutional Animal Care and Use Committee of Dalian Medical University.

\section{PLX3397 and minocycline treatment}

PLX3397 was dissolved in 0.1\% DMSO (diluted with PBS) [16]. PLX3397 (40 mg/kg/day) was administered to mice by gavage 7 days prior to rotenone injection (1.5 $\mathrm{mg} / \mathrm{kg} /$ day, i.p., daily). Based on previous reports and our pilot study, the number of microglia in the PLX3397-treated mice was reduced to approximately $70 \%$ of that in control mice at this time point $[16,17]$. After 7 days of initial PLX3397 administration, mice ( $n$ = 12 in each group) received PLX3397 30 mins prior to rotenone by every other day until the end of the experiment. Minocycline (dissolved in PBS, $50 \mathrm{mg} / \mathrm{kg} /$ day) was administered (i.p.) to mice 2 days before rotenone $(n=$ 11). After 2 days of treatment, minocycline was injected $30 \mathrm{~min}$ prior to rotenone by consecutive 3 weeks. The chosen of concentrations of PLX3397 and minocycline was based on previous reports $[16,18]$. Mice in control group were given equal amounts of $0.1 \%$ DMSO (diluted with PBS).

\section{Morris water maze test}

Morris water maze (MWM) test was performed as described previously $[19,20]$. The test included the navigation test and the spatial probe test. In the spatial navigation test, a circular platform was placed in the middle of one quadrant ( $1 \mathrm{~cm}$ below the water surface). In one trial, mice were randomly placed in one of the quadrants and were allowed to swim until they found the platform or for a maximum $90 \mathrm{~s}$. Mice were gently guided onto the platform if they could not find the platform within $90 \mathrm{~s}$, and their latencies were recorded as 90 s. All mice were given a break of $5 \mathrm{~min}$ on the platform between trials. There were four trials per day for each mouse, and the mice were tested for 4 days. A video camera was used to record the swimming paths of mice. Different parameters for evaluating learning performance, such as latency for escape and traveled distance were analyzed by using the tracking software (NoldusEtho Vision system, version 5, Everett, WA, USA).

On the fifth day, the spatial probe test for spatial memory function was performed. Briefly, the platform was removed and mice were permitted to navigate in the pool freely for $60 \mathrm{~s}$. Then, different parameters, including the time of mice spent in different quadrants, the latency to initially cross the position where the platform was located and the total number of platform crossings were recorded and analyzed by using the tracking software (NoldusEtho Vision system, version 5).

\section{Novel objective recognition}

Novel objective recognition (NOR) test was conducted based on a previous protocol [21]. In brief, mice were trained over 3 days (3 times per day) to discriminate a novel object from a familiar one. On the first day, mice were put in an empty chamber and permitted to move freely. On the following day, mice were allowed to explore two the same objects placed in opposite corners of the chamber for $5 \mathrm{~min}$. On the last day, mice were put back in the chamber and were permitted to explore a familiar object (the same object as day 2) and a new object with different colors and shapes from the familiar object. After each test, $70 \%$ ethanol was used to thoroughly clean the chamber and objects. The time the mice spent exploring familiar and novel objects was recorded, and the recognition index was calculated by using the following formula.

Recognition index $=\frac{\text { Time spent exploring novel object }}{\text { Time spent exploring both novel and familiar objects }} \times 100 \%$

\section{Passive avoidance test}

The passive avoidance test was done based on previous protocol [22]. In brief, mice were put in a chamber that was separated into light and dark compartments (the 
same size) by a guillotine door. On the first day, the guillotine door between the light and dark compartments was opened and mice were permitted to move freely for $5 \mathrm{~min}$ in both compartments of the chamber. The next day, mice were put in the light compartment. After $60 \mathrm{~s}$, the guillotine door was opened, and mice were permitted to move to the dark compartment freely. Once the mice entered, the guillotine door was closed and an electric shock was given $(0.3 \mathrm{~mA}, 5 \mathrm{~min})$. This test was repeated with 10-min intervals until the latency to enter the dark compartment reached 120 s. On the last day, mice were placed in the light compartment. Sixty seconds later, the guillotine door was opened and the latency of mice to enter the dark compartment (stepthrough latency) and the number of total entrances (step-through number) were recorded.

Immunohistochemistry and immunofluorescence staining Mice in each group were perfused transcardially with PBS, followed by $4 \%$ paraformaldehyde and then the brains were collected. Brain samples were postfixed with $4 \%$ paraformaldehyde at $4{ }^{\circ} \mathrm{C}$ for $48 \mathrm{~h}$, and then transferred to $30 \%$ sucrose in PBS before sectioning. Free-floating coronal sections $(30 \mu \mathrm{m})$ containing hippocampal and cortical regions were used for immunohistochemistry and immunofluorescence staining as described previously [23, 24]. Briefly, brain sections were blocked in $0.25 \%$ Triton/PBS containing $4 \%$ goat serum for $2 \mathrm{~h}$ and then incubated with anti-PSD-95, anti-Neu$\mathrm{N}$, anti-Iba-1, anti-GFAP or anti-Ser129-phosphorylated $\alpha$-synuclein antibodies in PBS containing $0.1 \%$ Triton X100 at $4{ }^{\circ} \mathrm{C}$ for an additional $24 \mathrm{~h}$. Then, the sections were washed three times prior to incubation with an appropriate biotinylated or Alexa-594-conjugated secondary antibody. Immunohistochemical staining was visualized by using 3,3'-diaminobenzidine. Digital images were acquired ( $\times 10$ and $\times 40$ magnification for immunohistochemistry and immunofluorescence staining, respectively) under an Olympus microscope (BX51; Olympus, Tokyo, Japan) using an attached digital microscope camera (DP72; Olympus).

The densities of Iba-1, PSD-95, and GFAP immunostaining from two to three brain sections with $120-\mu \mathrm{m}$ intervals from each mouse in each group were measured by using ImageJ software [24-26]. Briefly, the image was first converted into the grayscale picture, and the background was adjusted before the quantifying area was selected for the measurement of the total pixels. The relative density of the staining was compared based on the density of the total pixels of a certain brain region (total pixels/area). The quantification of the staining was corrected for background staining by subtracting the pixels without primary antibody.

\section{Automated counting assessment of neurodegeneration} The number of $\mathrm{Neu}-\mathrm{N}^{+}$neurons in mice among the groups was quantified by the automated counting method in ImageJ software $[19,24]$.

\section{TUNEL assay}

In Situ Cell Death Detection Kit was used to perform TUNEL assays in free-floating coronal sections $(30 \mu \mathrm{m})$ containing hippocampal and cortical regions [22, 27]. $\mathrm{TUNEL}^{+}$cells were observed using a fluorescence microscope ( $\times 40$ magnification). The mean number of TUNEL $^{+}$cells in each mouse was obtained by counting three coronal sections with $120 \mu \mathrm{m}$ intervals by using ImageJ software.

\section{Western blot analysis}

For Western blot analysis, mice were perfused transcardially with PBS to remove the blood. The brains were collected and hippocampal, and the cortical brain regions were dissected immediately on ice. Tissue samples including the hippocampus and cortex were homogenized by using ice-cold RIPA buffer with a protease inhibitor mixture and then centrifuged at $10,000 \times g$. After $10 \mathrm{~min}$ of centrifugation, protein concentrations were measured in the collected supernatants by using a BCA protein assay kit. Samples containing equal amounts of protein from each group were separated by $4-12 \%$ SDSPAGE, and then, immunoblot analysis was performed using anti-PSD-95, anti-Neu-N, anti- $\alpha$-synuclein, and anti- $\alpha$-synuclein (phospho S129) antibodies at $4{ }^{\circ} \mathrm{C}$ for $24 \mathrm{~h}$. After washing three times with PBST, the membranes were incubated with appropriate HRP-linked anti-rabbit or mouse IgG. The signal was detected by ECL reagents, and relative density of blots was quantified using ImageJ software.

\section{Real-time PCR analysis}

For RT-PCR analysis, mice in each group $(n=6)$ were perfused transcardially with PBS to remove the blood. The hippocampal and cortical brain regions were dissected immediately on ice and then transferred to liquid nitrogen, followed by a $-80^{\circ} \mathrm{C}$ freezer. RNA was isolated from the hippocampal and cortical samples by using TRIzol reagent. Quantitative analysis of RNA was performed by using Nanodrop spectrophotometer. A total 1- $\mu$ g RNA from each sample was used for complementary DNA (cDNA) synthesis using MuLV reverse transcriptase and oligo dT primers according to previous reports $[28,29]$. The reaction conditions were set as $25^{\circ} \mathrm{C}$ for $5 \mathrm{~min}, 42^{\circ} \mathrm{C}$ for $60 \mathrm{~min}$, and $70^{\circ} \mathrm{C}$ for $15 \mathrm{~min}$. SYBR Premix Ex TaqTM II and a Takara Thermal Cycler Dice $^{\text {tm }}$ Real Time System were subsequently used for real-time PCR detection based on the manufacturer's protocols. The primers were designed with Vector NTI 
software and validated for efficacy through melting curve analyses. The sequences of the primers were the follows: GAPDH F (5'-TTCAACGGCACAGTCAAGGC-3'; 300 nM), GAPDH $\mathrm{R}$ (5'-GACTCCACGACATACTCA GCACC-3'; $300 \mathrm{nM}), \quad$ TNF $\alpha$ F $\left(5^{\prime}\right.$-GACCCTCACA CTCAGATCATCTTCT-3'; $300 \mathrm{nM}), \quad$ TNF $\alpha$ R (5'CCTCCACTTGGTGGTTTGCT-3'; $300 \mathrm{nM})$, IL-1 $\beta$ F (5'-CTGGTGTGT GACGTTCCCATTA-3'; $300 \mathrm{nM}$ ), IL-1 $\beta$ R (5'-CCGACAGCACGAGGCTTT-3'; 300 nM), iNOS F(5'-CTGCCCCCCTGCTCACTC-3'; $300 \mathrm{nM})$, and iNOS R (5'-TGGGAGGGGTCGTAATGTCC-3'; $300 \mathrm{nM})$. The following PCR conditions were used: $95^{\circ} \mathrm{C}$ for $10 \mathrm{~s}, 55^{\circ} \mathrm{C}$ for $30 \mathrm{~s}$, and $72{ }^{\circ} \mathrm{C}$ for $30 \mathrm{~s}$ for 40 cycles (for a final reaction volume of $25 \mu \mathrm{l}$ ). All samples were tested in duplicate and normalized to GAPDH using the $2^{-\Delta \Delta \mathrm{Ct}}$ method. Fold changes for each treatment were normalized and are shown as percentages of the control.

\section{GSH and MDA assay}

The tissue samples of mice perfused with PBS only were homogenized in ice-cold lysis buffer containing $20 \mathrm{mM}$ Tris ( $\mathrm{pH} 7.5), 150 \mathrm{mM} \mathrm{NaCl}, 1 \%$ Triton $\mathrm{X}-100$, and protease inhibitor mixture. After 10 min of centrifugation at $10,000 \times g\left(4{ }^{\circ} \mathrm{C}\right)$, the contents of GSH and MDA in the collected supernatant were measured by using commercial kits based on the protocol provided by the manufacturer [30].

\section{Statistical analysis}

Data were expressed as the mean \pm SEM. Except for the MWM test, comparison of means among two or more groups was conducted using one-way (one parameter) or two-way ANOVA (two parameters). Subsequently, Tukey's post hoc test was used for pairwise comparisons between means once ANOVA showed significant differences. The MWM test data were analyzed using repeated measures ANOVA. Fisher's PLSD tests were used for comparing group means only when a significant $F$ value was observed in the overall ANOVA. A $p$ value less than 0.05 was considered statistically significant.

\section{Results}

\section{Rotenone dose-dependently impairs cognitive capacity of} mice

To determine whether rotenone-treated mice displayed cognitive dysfunction, the MWM, novel objective recognition, and passive avoidance tests were performed after 3 weeks of rotenone exposure (Fig. 1a). In MWZ test, mice in the control group exhibited normal spatial leaning ability as indicated by the time-dependent decreases in escape latency and traveled distance (Fig. 1b). We did not find a significant difference in escape latency and traveled distance between $0.75 \mathrm{mg} / \mathrm{kg}$ rotenone-treated mice and vehicle controls, although an increasing trend was observed (Fig. 1b). However, $1.5 \mathrm{mg} / \mathrm{kg}$ rotenone significantly elevated the escape latency as the rotenonetreated mice showed a longer time to locate the platform than the control mice (Fig. 1b). Consistently, $1.5 \mathrm{mg} / \mathrm{kg}$ rotenone also markedly increased the traveled distance of mice (Fig. 1c), indicating impaired spatial learning function. No significant difference was observed in swimming speed for the mice (Fig. 1d), which excluded the possibility that the differences in MWM performance among the groups were due to locomotor deficits. The spatial probe test was subsequently performed to evaluate the spatial memory capacity of mice. Mice that received $1.5 \mathrm{mg} / \mathrm{kg}$ rotenone displayed increased latency for the first platform crossing and a reduced total number of platform crossings and percentage of time spent in the target quadrant compared with control group (Fig. 1e-g), indicating impaired memory ability. However, mice in the $0.75 \mathrm{mg} / \mathrm{kg}$ rotenone and control group failed to show significant differences in the spatial probe test (Fig. 1e-g).

To further confirm the impaired cognitive capacity of mice, the novel objective recognition and passive avoidance tests were subsequently performed. Consistently, rotenone at $1.5 \mathrm{mg} / \mathrm{kg}$ significantly reduced the recognition index and step-through latency and increased the error times in step-through compared to vehicle controls (Fig. 1h-j). No significant difference in recognition index, step-through latency, and number was observed between $0.75 \mathrm{mg} / \mathrm{kg}$ rotenone-treated mice and control group. These results suggest that $1.5 \mathrm{mg} / \mathrm{kg}$ rotenoneinduced PD model mice displayed impaired cognitive performance.

\section{Rotenone dose-dependently induces neuronal damage}

Cognitive dysfunction in PD is associated with abnormal neuronal damage, especially in the hippocampal and cortical regions [31, 32]. To investigate whether rotenone-induced cognitive deficits were associated with hippocampal and cortical neuron damage, neuronal cells were immunostained with neuron-specific anti-Neu-N antibody. As illustrated in Fig. 2a-e, $1.5 \mathrm{mg} / \mathrm{kg}$ rotenone treatment significantly reduced the number of Neu-N+ neurons in the hippocampal and cortical regions of mice compared with the vehicle control treatment. Additionally, synapses are critical for neuron-neuron communication and cognitive function. Reduced expression of key synaptic proteins, such as PSD-95, is significantly correlated with cognitive decline in neurodegenerative disorders $[19,20]$. In agreement with neuronal loss, immunohistochemical analysis revealed a reduced density of hippocampal and cortical PSD-95 immunostaining in $1.5 \mathrm{mg} / \mathrm{kg}$ rotenone-treated mice (Fig. 2a-e and Supplementary Fig. 1). 


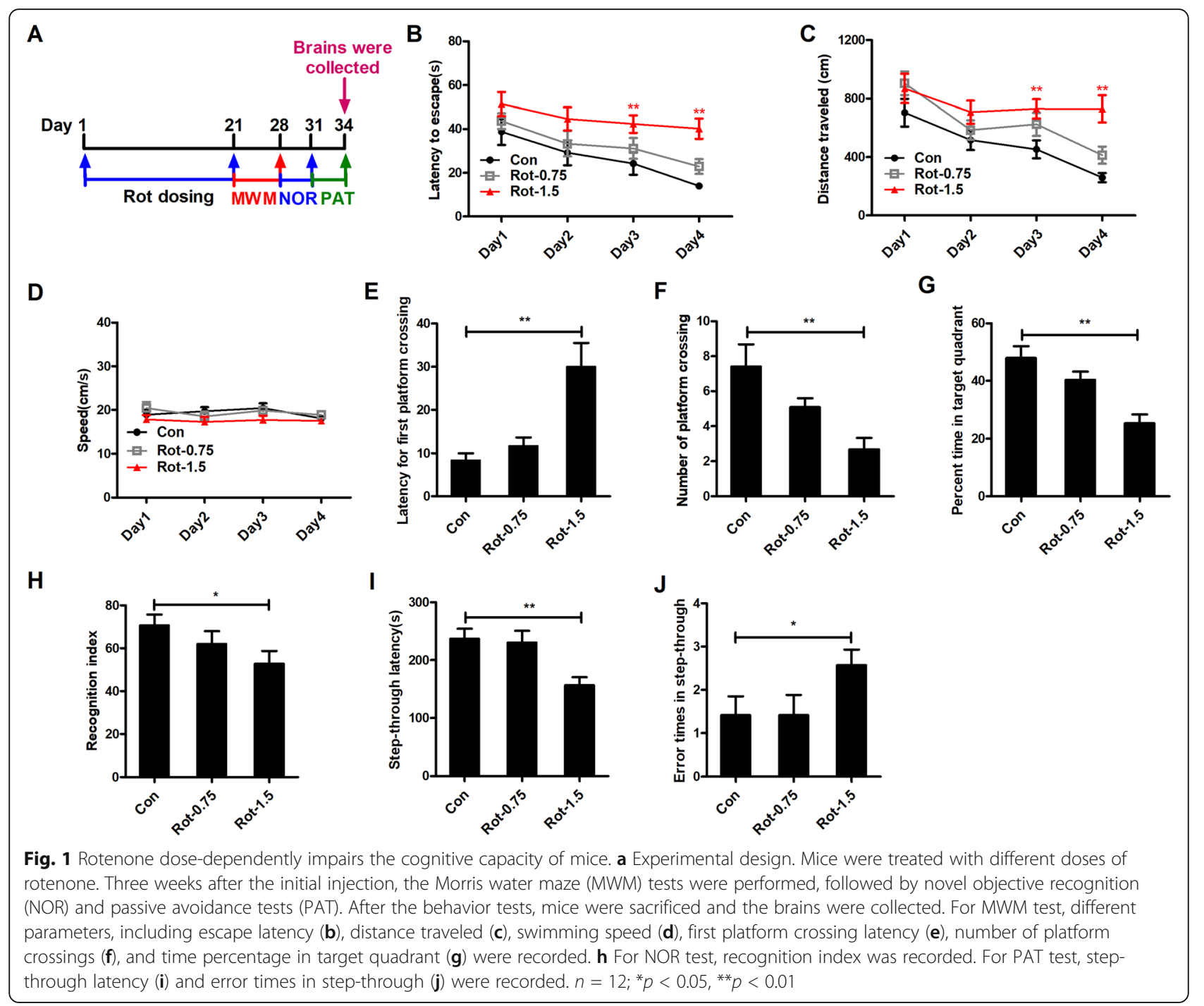

To further confirm the damage to neurons in rotenone-treated mice, the levels of Neu-N and PSD95 were determined. As shown in Fig. $2 \mathrm{f}-\mathrm{h}$, rotenone at 1.5 $\mathrm{mg} / \mathrm{kg}$ reduced the protein levels of Neu-N and PSD-95 in the hippocampal and cortical regions of mice. The comparison of Neu- $\mathrm{N}^{+}$cell number, PSD95 immunostaining density and expression of Neu-N and PSD95 between the $0.75 \mathrm{mg} / \mathrm{kg}$ rotenone-treated mice and vehicle-treated controls showed no significant differences (Fig. 2a-h).

In addition to neuronal damage, $\alpha$-synuclein accumulation and phosphorylation, especially at the Ser129 site, also contribute to cognitive deficits in PD [33]. Immunofluorescence staining showed elevated phosphorylation of $\alpha$-synuclein at Ser129 in the hippocampus and cortex of $1.5 \mathrm{mg} / \mathrm{kg}$ rotenone-treated mice compared with control group (Fig. 2i). Fluorescence density analysis of
Ser129-phosphorylated $\alpha$-synuclein immunostaining confirmed this observation (Fig. 2j).

\section{Microglial activation precedes neuronal damage in rotenone-treated mice}

To investigate whether microglial activation contributes to rotenone-induced cognitive deficits in mice, microglia were immunostained with a microglial marker, Iba-1, after 3 weeks of rotenone exposure. As seen in Fig. 3a, microglial cells in the hippocampus and cortex of 1.5 $\mathrm{mg} / \mathrm{kg}$ rotenone-injected mice exhibited hypertrophic morphology and increased Iba-1 expression, indicating microglial activation. Quantitative analysis revealed $45.4 \%$ and $39.7 \%$ increases Iba-1 density in the hippocampus and cortex, respectively, of $1.5 \mathrm{mg} / \mathrm{kg}$ rotenonetreated mice compared with controls (Fig. 3b, c). No 


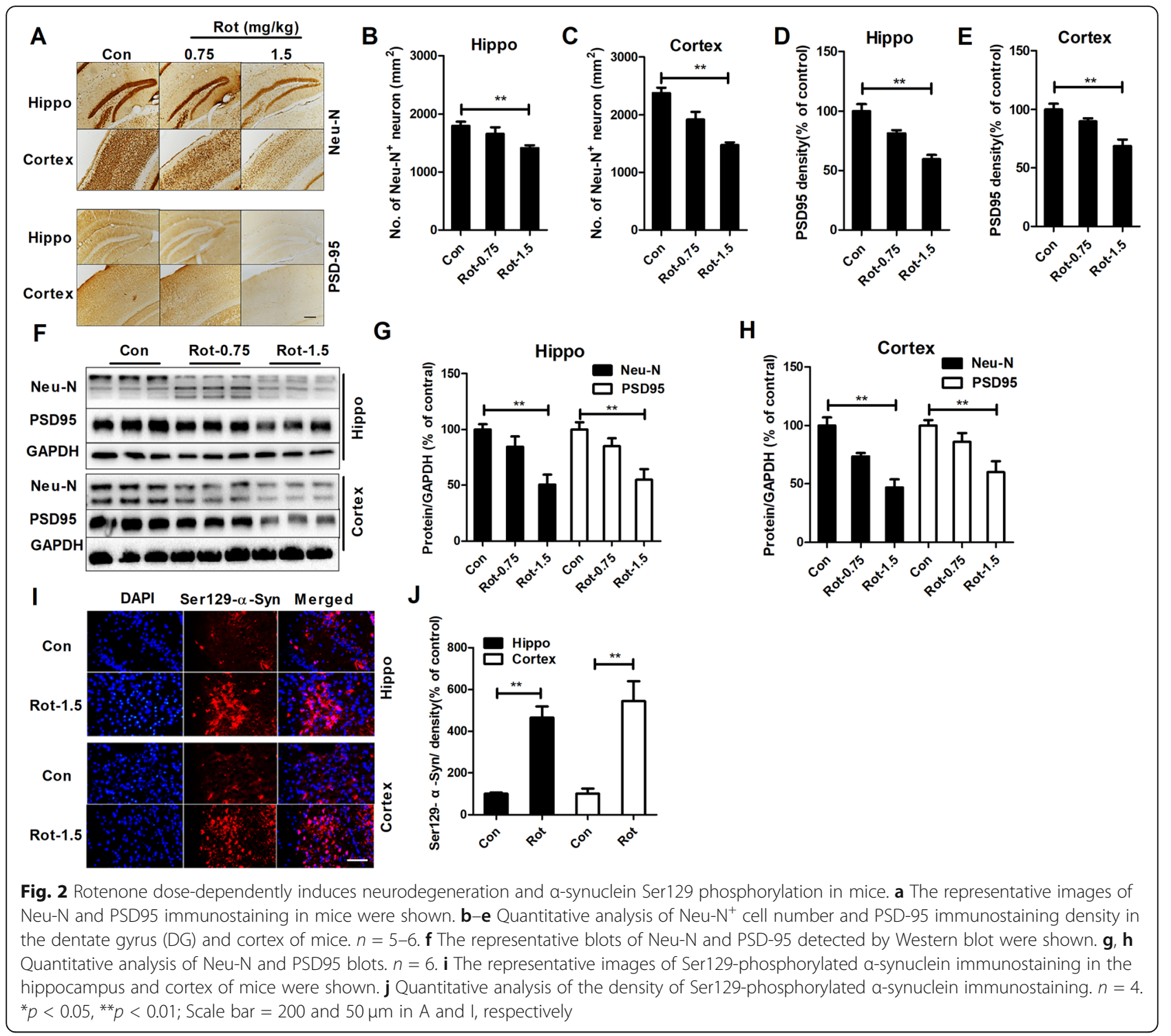

significant microglial activation was observed in 0.75 $\mathrm{mg} / \mathrm{kg}$ rotenone-injected mice (Fig. 3a-c).

To determine the time sequence of microglial activation and neuronal damage in rotenone-treated mice, a time course study was performed at the indicated time points of rotenone intoxication (Fig. 3d). The results showed that microglial activation in the hippocampal and cortical regions of mice occurred as early as 1 week after rotenone exposure and was sustained up to 3 weeks (Fig. 3e). Quantitative analysis of Iba-1 immunostaining density revealed $21.1 \%, 32.6 \%$, and $54.9 \%$ increases in the hippocampus and $22.8 \%, 42.0 \%$, and $65.3 \%$ increases in the cortex after 1,2 , and 3 weeks of rotenone injection, respectively (Fig. 3f, g). In contrast, neuronal damage as evidenced by decreased $\mathrm{Neu}-\mathrm{N}^{+}$cell number and
PSD95 immunostaining density was observed after 2 weeks of rotenone injection (Fig. $3 \mathrm{e}-\mathrm{g}$ ). These results suggested that rotenone-induced microglial activation precedes neurodegeneration.

\section{PLX3397 and minocycline attenuate rotenone-induced} cognitive deficits in mice

To determine whether microglial activation contributes to cognitive impairment, rotenone-injected mice were administered PLX3397 or minocycline. PLX3397 is an inhibitor of colony-stimulating factor 1 receptor (CSF1R) and can efficiently reduce the number of microglia in the brains of mice [17]. Minocycline is a widely used antibiotic that could suppress neuroinflammation in a variety of rodent models of neurodegenerative diseases 


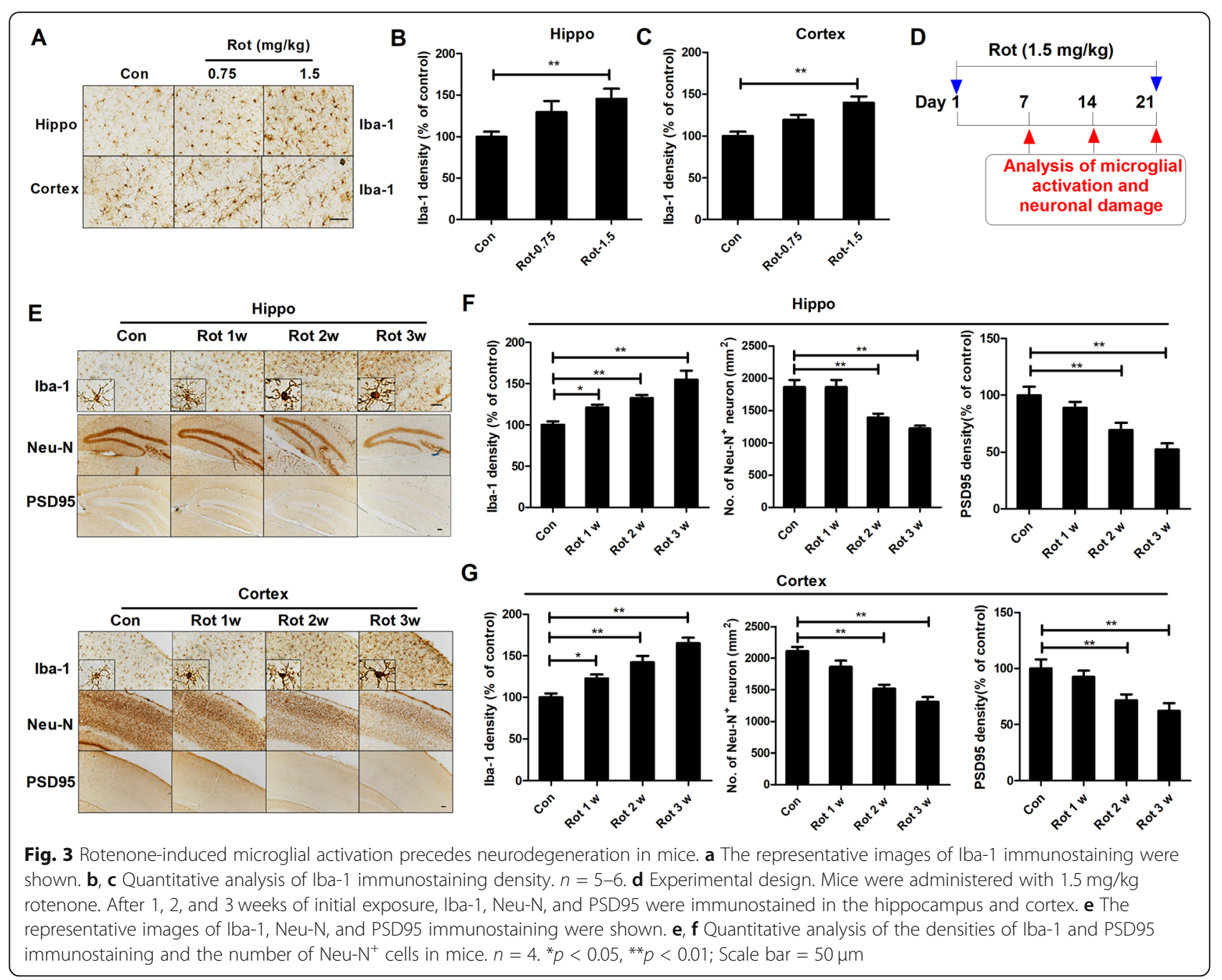

[34]. Consistent with a previous report, PLX3397 treatment significantly reduced the number of microglia in the hippocampus and cortex when compared to vehicletreated mice (Supplementary Fig 2A-C). Minocycline also efficiently blocked rotenone-induced microglial activation in the hippocampus and cortex of mice (Supplementary Fig 2D-F). Subsequently, cognitive performance was measured in mice treated with rotenone with or without PLX3397 and minocycline. In agreement with the results of Fig. 1, impaired learning and memory performance of mice was detected in MWM test after rotenone $(1.5 \mathrm{mg} / \mathrm{kg})$ treatment. Interestingly, PLX3397 and minocycline significantly ameliorated rotenone-induced learning and memory impairments by showing reduced escape latency, traveled distance, and latency for first platform crossing as well as the recovered platform crossing number and percentage of time spent in target quadrant in combined PLX3397 or minocycline and rotenone-treated mice compared with rotenone alone group (Fig. $4 \mathrm{a}-\mathrm{C}$ and $\mathrm{e}-\mathrm{g}$ ). There were no significant differences in swimming speed among the groups, which excluded the possibility that the protective effects of PLX3397 and minocycline-afforded were caused by recovered motor activity (Fig. 4d).

To further confirm the protective effects of PLX3397 and minocycline against rotenone-induced cognitive deficits, novel objective recognition and passive avoidance tests were performed. In agreement with that of MWZ test, PLX3397, and minocycline significantly elevated the recognition index of rotenone-treated mice in the novel objective recognition test (Fig. 4h). Minocycline also elevated the step-through latency and decreased the error times of step-through in rotenone-treated mice (Fig. 4i). Although reduced error times in step-through and increased step-through latency were observed in PLX3397 and rotenone cotreated mice compared with rotenone 


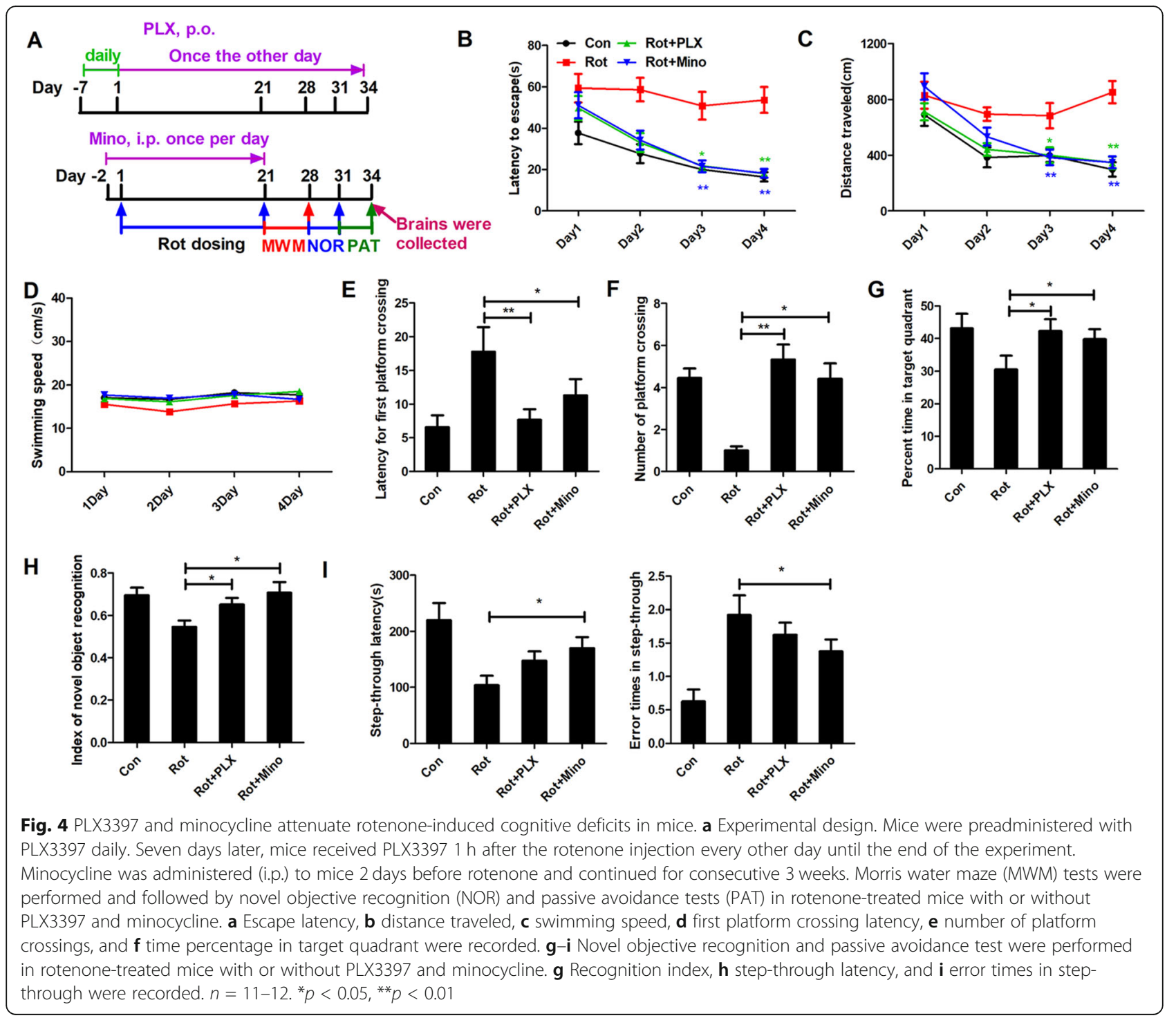

alone group, the difference did not reach statistical significance (Fig. 4i). These results suggested that microglial activation contributed to rotenone-induced cognitive deficits in mice.

\section{PLX3397 and minocycline attenuate rotenone-induced neuronal damage and Ser129 phosphorylation of a- synuclein}

The neuroprotective effects of PLX3397 and minocycline were subsequently determined. Consistent with their attenuation pf cognitive decline, PLX3397 and minocycline also mitigated rotenone-induced neuronal damage in mice. Restored Neu- $\mathrm{N}^{+}$cell numbers and increased PSD95 staining densities were observed in both the hippocampal and cortical regions of PLX3397 or minocycline and rotenone cotreated mice compared with rotenone alone group (Fig. 5a-e and Supplementary Fig. 3 ), indicating neuroprotection. This conclusion was further supported by analysis of the expression of Neu-N and PSD95 (Fig. 5f-h).

In addition to neuroprotection, PLX3397 and minocycline also mitigated the Ser129-phosphorylation of $\alpha$-synuclein by showing reduced expression of Ser129-phosphorylated $\alpha$-synuclein in PLX3397 or minocycline and rotenone cotreated mice compared with rotenone alone group (Fig. $5 \mathrm{i}, \mathrm{j}$ ).

\section{PLX3397 and minocycline attenuate rotenone-induced astroglial activation and proinflammatory factor production}

A recent study revealed that microglial activation can induce astrocytes into a neurotoxic activation status in 


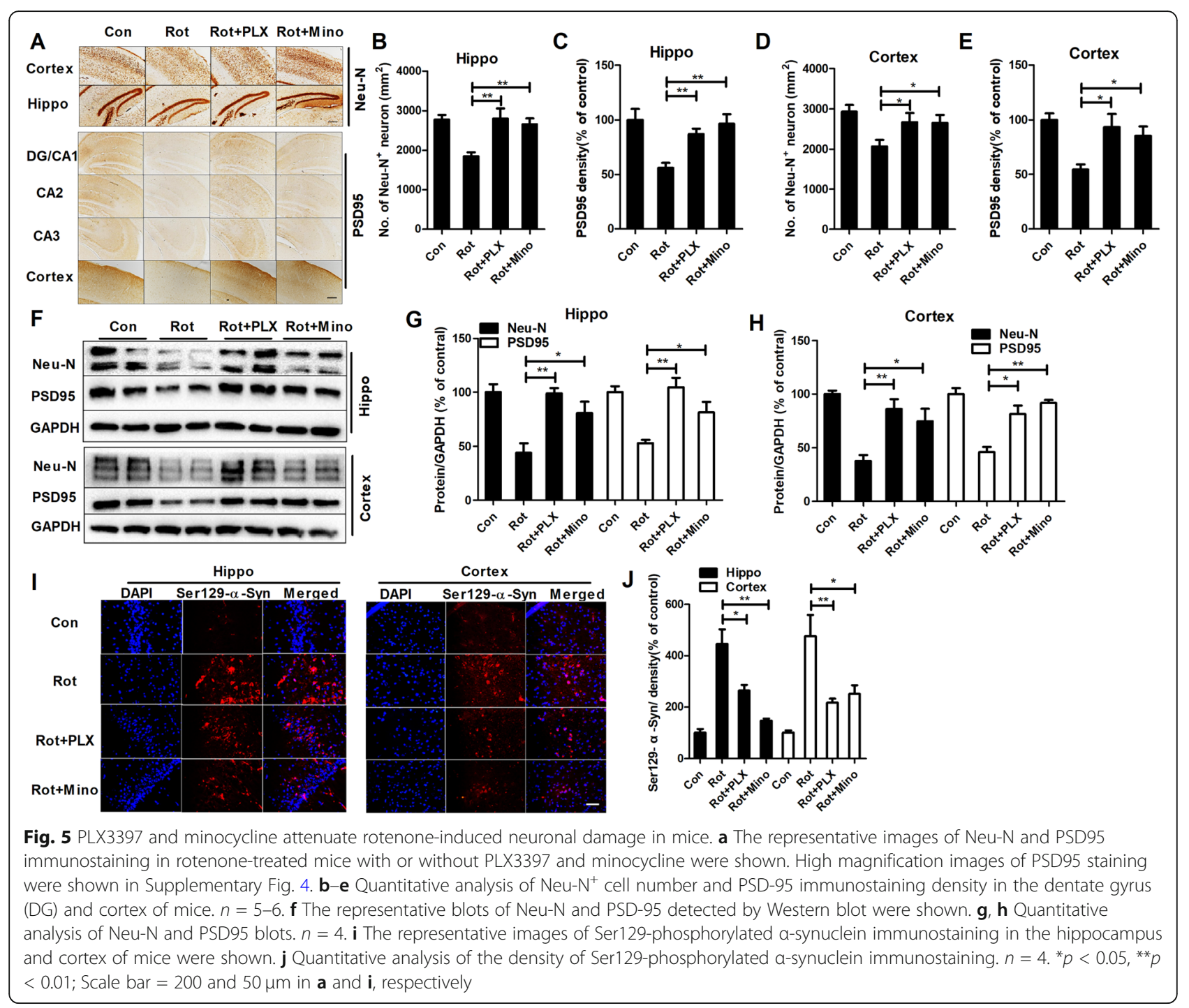

multiple neurological disorders [11]. To determine whether microglial depletion by PLX3397 or inactivation by minocycline could suppress astroglial activation, immunohistochemistry using anti-GFAP antibody, was performed in mice. As seen in Fig. 6a, astroglial cells in the hippocampus and cortex of rotenone-treated mice displayed hypertrophied morphology and intensified GFAP immunostaining, which indicated astroglial activation. Densitometric analysis of GFAP staining further supported this conclusion (Fig. 6b, c). Interestingly, astrocytes in PLX3397 or minocycline and rotenonecotreated mice showed normal morphology and reduced expression of GFAP compared with that of rotenone alone group, suggesting that the activation of astrocytes is blocked by PLX3397 or minocycline (Fig. 6a-c).

The production of proinflammatory factors is a common mechanism by which activated glial cells damage neurons in the central nervous system. To determine whether microglial depletion by PLX3397 or inactivation by minocycline could dampen the production of proinflammatory factors, the gene expression levels of iNOS, TNF $\alpha$, and IL- $1 \beta$ were measured. As seen in Fig. $6 \mathrm{~d}$, e, rotenone injection increased the gene transcript levels of iNOS, TNF $\alpha$, and IL- $1 \beta$ in both the hippocampus and cortex of mice, and these increases were significantly reduced by PLX3397 and minocycline.

\section{PLX3397 and minocycline attenuate rotenone-induced oxidative stress}

Oxidative stress usually coexists with neuroinflammation. To determine whether microglial depletion by PLX3397 or inactivation by minocycline could dampen oxidative stress, the contents of GSH and MDA were measured. In agreement with reduced production of 


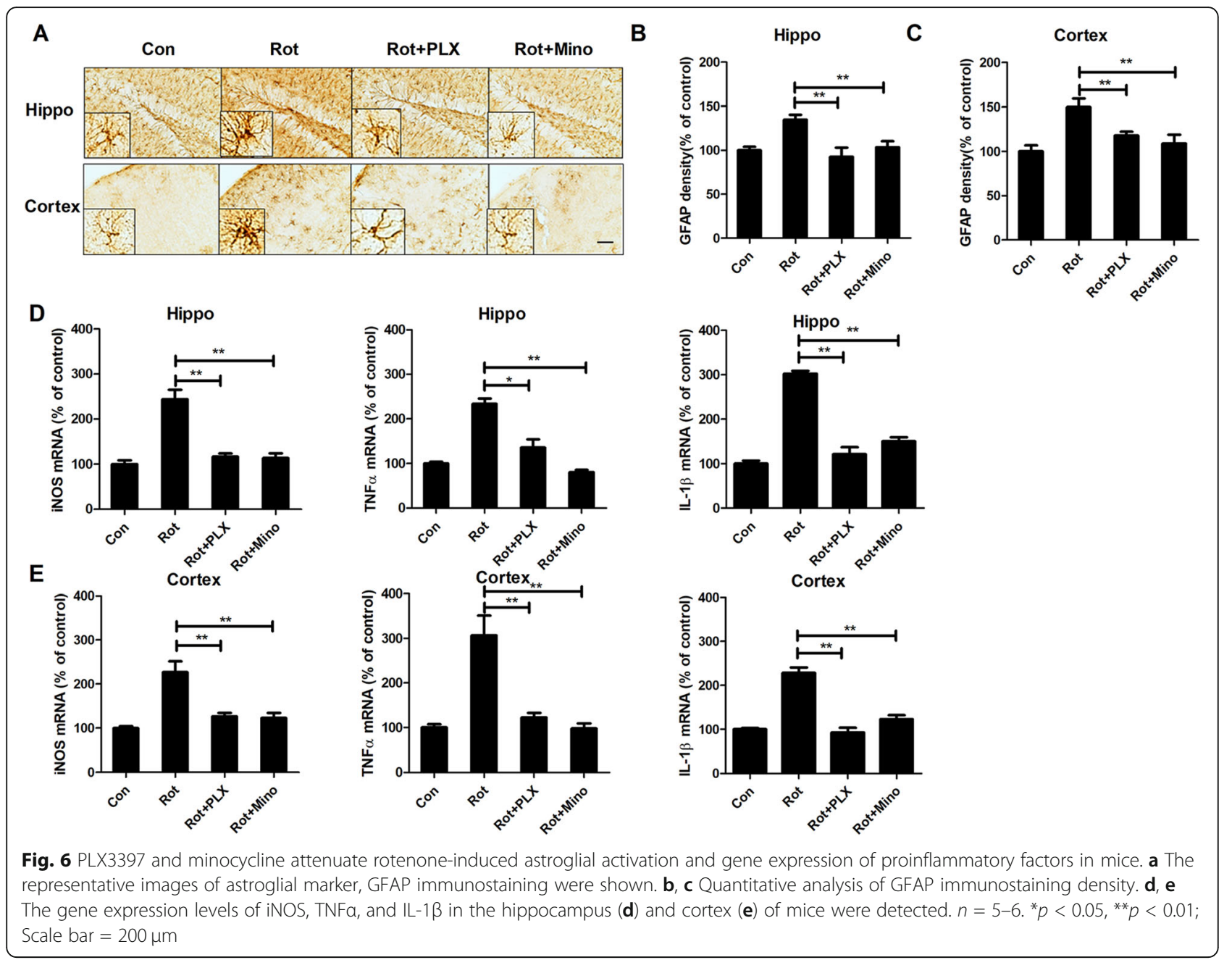

proinflammatory factors, rotenone-induced lipid peroxidation was also mitigated by PLX3397 and minocycline by showing decreased MDA levels (Fig. 7a, c) and recovered GSH contents (Fig. 7b, d) in PLX3397 or minocycline and rotenone-cotreated mice compared with rotenone alone group.

\section{PLX3397 and minocycline attenuate rotenone-induced neuronal apoptosis}

The effects of PLX3397 and minocycline on neuronal apoptosis were further determined in rotenone-treated mice. TUNEL staining revealed a high number of $\mathrm{TUNEL}^{+}$cells in the hippocampal and cortical regions of rotenone-treated mice compared with those of control group (Fig. 8a, b), indicating that apoptosis occurs after rotenone exposure. Immunofluorescence staining with antibodies against MAP2, Iba-1, and GFAP antibodies combined with TUNEL labeling was further performed to observe the distribution of apoptosis among neurons, microglia, and astrocytes, respectively. Results showed that rotenone-induced increase in TUNEL staining in the hippocampus and cortex was mainly concentrated in $\mathrm{MAP2}^{+}$cells, indicating neuronal apoptosis (data not shown). Interestingly, PLX3397 and minocycline treatment markedly decreased rotenone-induced neuronal apoptosis by showing reduced number and percentage of TUNEL ${ }^{+}$cells in PLX3397 or minocycline and rotenone co-treated mice compared with rotenone alone group (Fig. 8a, b).

It is well documented that apoptosis is controlled by multiple proteins, such as the Bcl-2 family and caspase [35]. Bcl-xL and Bax, two key members of the Bcl-2 family, display anti-apoptotic and proapoptotic functions, respectively [36]. Caspase-3, a member of the caspase family, is the main executor of apoptosis [35]. The effects of PLX3397 and minocycline on the expression of these apoptotic regulators were determined by using Western blotting. Consistent with the increase in TUNEL staining, rotenone treatment caused an increase of active caspase- 3 and Bax expression and a decrease in 
A

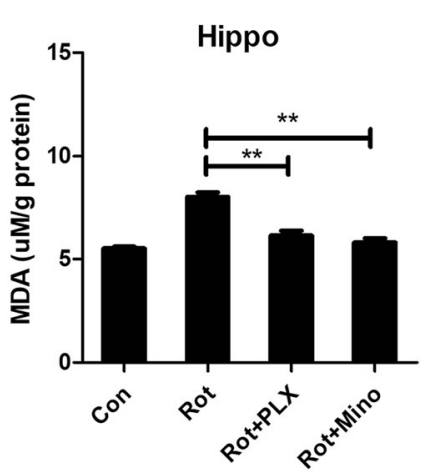

C

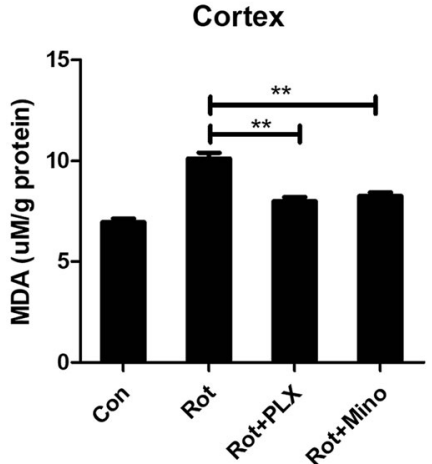

B

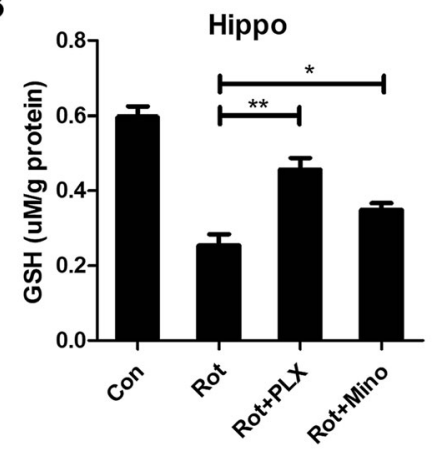

D

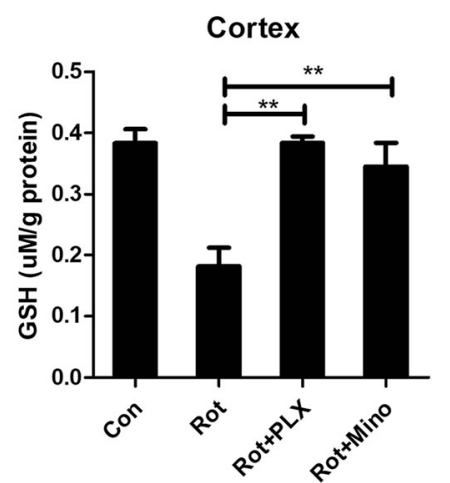

Fig. 7 PLX3397 and minocycline attenuate rotenone-induced oxidative stress in mice. The MDA (a, c) and GSH (b, d) contents in rotenonetreated mice with or without PLX3397 and minocycline were determined. $n=6 .{ }^{*} p<0.05$, ${ }^{* *} p<0.01$

Bcl-xL expression in mice (Fig. 8c-e). In contrast, mice treated with combined PLX3397 or minocycline and rotenone displayed reduced the expression of caspase- 3 and Bax as well as elevated expression of Bcl-xL compared with those of mice treated with rotenone alone (Fig. $8 \mathrm{c}-\mathrm{e}$ ), indicating attenuated apoptosis.

\section{Discussion}

In this study, we provided strong evidence to support that microglial activation contributed to cognitive decline in a mouse PD model generated by rotenone. Four salient features were observed: (1) rotenone-induced microglial activation preceded neurodegeneration in mice; (2) microglial depletion by PLX3397 and inactivation by minocycline significantly ameliorated rotenoneinduced cognitive deficits and neuronal damage in mice; (3) PLX3397 and minocycline suppressed astroglial activation, production of proinflammatory factors, and oxidative stress in rotenone-treated mice; and (4) PLX3397 and minocycline abrogated rotenone-induced neuronal apoptosis in mice.

PD is traditionally recognized as a movement disorder with progressive loss of nigral dopaminergic neurons [37]. However, accumulating evidence suggests that PD is a heterogeneous multisystem disorder and patients with PD display both motor deficits and multiple nonmotor symptoms [19, 38]. Cognitive impairments are one of the most common nonmotor symptoms in patients with PD. Clinical studies have revealed that $25 \sim 46.8 \%$ of newly diagnosed patients exhibit mild cognitive deficits, and up to $80 \%$ exhibit dementia in the late stage of the disease $[39,40]$. A postmortem study in PD patients indicates that limbic and cortical neuron damage and Lewy body pathology correlate with cognitive decline [41]. However, studies in widely used parkinsonian animal model induced by 1-methyl-4-phenyl-1,2,3,6tetrahydropyridine (MPTP) generated mixed results, which greatly hampered the progress of mechanical studies on cognitive deficits. Although cognitive decline was reported in MPTP-induced mouse model in previous reports $[42,43]$, Fifel et al. found no significant decrease in cognitive alterations in either acute or chronic MPTP-treated mice [44]. Our preliminary data also showed that MPTP failed to damage learning and memory capacity in mice (data not shown), although significant dopaminergic neurodegeneration was reported in this model $[45,46]$. The rotenone-induced mouse PD model is also widely used. However, mixed results regarding the effects of rotenone on cognition in mice have been generated. Alabi et al. reported that daily doses of rotenone $(2.5 \mathrm{mg} / \mathrm{kg}$, i.p) for 4 weeks impaired memory in mice as shown by a significantly impaired 


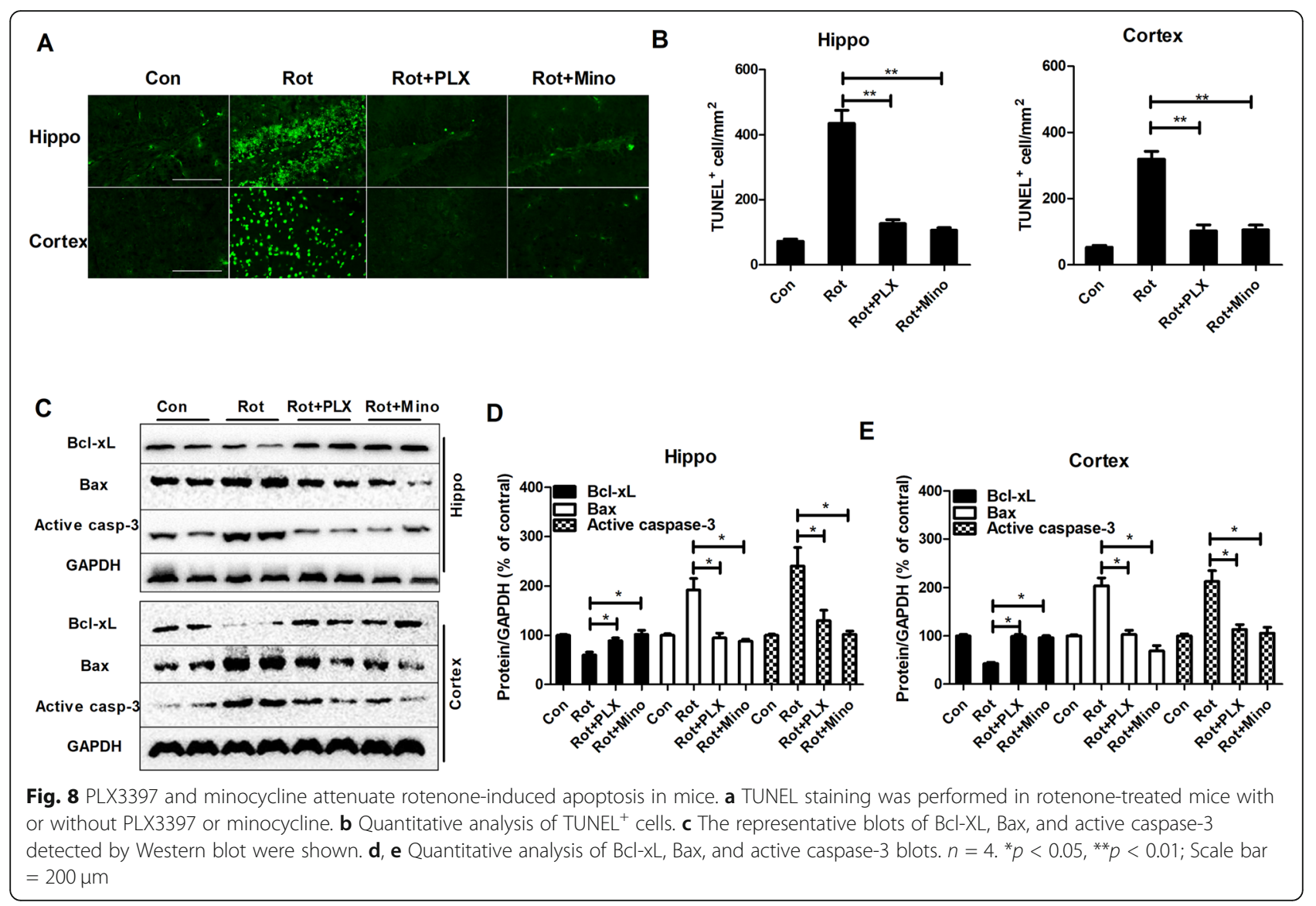

performance in the Y-maze test compared with that of vehicle controls [47]. In contrast, Jia and colleagues found that intragastric delivery of rotenone $(5 \mathrm{mg} / \mathrm{kg}$ ) for 3 months improved spatial learning and memory abilities of mice in the MWM test, although spatial memory ability was impaired at 1 month after treatment [48]. In this study, we further investigated the effects of rotenone on cognition in mice by using a subchronic dosing regimen. Results showed that rotenone dose-dependently decreased novel objective recognition, passive avoidance, and MWM performance in mice after 3 weeks of treatment. Furthermore, elevated neuronal damage, loss of synapses, and Ser129-phosphorylation of $\alpha$-synuclein were also detected in rotenone-injected mice, which was consistent with observations in PD patients.

The mechanisms underlying rotenone-induced cognitive dysfunction remain unclear. Inflammation has long been found to be inversely correlated cognitive decline $[20,49]$. Increasing evidence suggested that activated microglia is a key causative factor in inflammationmediated neurodegeneration and behavioral deficits [50]. Dysregulated microglial activation is reported to be able to increase pathological protein aggregation and impair synaptic pruning and neuron plasticity in key brain regions subserving cognition [51, 52]. In the present study, activated microglia were detected in the hippocampus and cortex of rotenone-induced mouse PD model. A time experiment revealed that microglial activation induced by rotenone preceded neuronal damage and $\alpha$-synuclein pathology in mice. Furthermore, microglial depletion by PLX3397 or inactivation by minocycline significantly reduced neuronal damage in the hippocampus and cortex of mice treated with rotenone. Consistently, neuroprotective effects of both PLX3397 and minocycline against rotenone-induced dopaminergic neurodegeneration were also observed in mice (data not shown). More importantly, PLX3397 and minocyclineafforded neuroprotection were associated with improved cognitive performance in rotenone-treated mice, indicating an important role of activated microglia in mediating cognitive dysfunction. In agreement with our findings, Cope and colleagues recently found that microglial activation plays an active role in obesity-associated cognitive decline since blocking microglial activation by minocycline prevented loss of dendritic spines and cognitive decline in obese mice [53]. Depletion of microglia by CSF1R inhibitors, such as PLX3397 and PLX5622, was also associated with improved cognitive performance in 
experimental mouse models of $\mathrm{AD}$ [54], intracerebral hemorrhage [55], and irradiation-induced memory deficits [56].

Microglia can become overactivated in response to certain injuries and release a variety of cytotoxic factors that cause neurotoxicity [11]. In addition, activated microglia have recently been shown to be able to induce astrocytes into a neurotoxic A1 status by releasing TNF $\alpha, \mathrm{IL}-1 \alpha$, and C1q to amplify neuronal damage [11]. Proinflammatory factors and reactive oxygen species (ROS) are considered to be critical to mediate neuroinflammatory damage since neutralization of proinflammatory factors or inhibition of ROS during neuroinflammation showed potent neuroprotection in a variety of neurodegeneration models [57]. Consistent with these findings, in this study, elevated astroglial activation, production of proinflammatory cytokines, and oxidative stress were observed in rotenonetreated mice. Furthermore, we demonstrated that microglial depletion by PLX3397 and inactivation by minocycline suppressed these toxic events and was accompanied by decreased apoptosis of neurons and expression of cleaved caspase- 3 and Bax as well as elevated expression of Bcl-xL. Our findings suggested that microglial activation contributed to cognitive deficits and neuronal apoptosis through neurotoxic astroglial activation, neuroinflammation, and oxidative damage. Consistent with our findings, endotoxin LPS, an inflammatory stimulator, has been reported to induce cognitive deficits in mice through neuroinflammation and neuronal apoptosis [21]. Inhibition of inflammatory cytokines, oxidative stress, and neuronal apoptosis in the hippocampus also ameliorated cognitive deficits in mouse model of AD [58], vascular dementia, and sepsis [59]. Notably, a pharmacological manipulation method (PLX3397 and minocycline) was used to block microglial activation in the current study, and we could not exclude the possibility that PLX3397 and minocycline might be have direct effects on astroglial activation, oxidative stress, or neuronal apoptosis. Further study focusing on this issue should be performed in the future.

It is interesting to compare the similar protective effects of minocycline and PLX3397 in this study. Minocycline is a semisynthetic tetracycline derivative that displays potent anti-inflammatory effects. Multiple studies have revealed that minocycline can dampen proinflammatory microglial activation (M1) and might simultaneously promote microglial M2 polarization in neuropathological conditions [60-62]. In contrast, PLX3397 is reported to directly deplete microglia in an apoptosis-dependent manner in the brains of mice [17]. Although microglial elimination by PLX3397 is not accompanied by an inflammatory response in the brain, PLX3397-treated mice exhibited robust reductions in the expression of many inflammatory genes, including
TNF- $\alpha$ and other cytokines, in response to LPS [17]. Consistently, Liang et al. reported that PLX3397 treatment significantly reduced the number of M1 phenotype-like microglia and production of proinflammatory factors in a mouse model of high-fat-diet (HFD)induced obesity [63]. Our preliminary data showed reduced expression of iNOS, a marker of M1 microglia, and elevated expression of the M2 microglial marker Arg-1 in the brains of mice treated with combined PLX3397 and rotenone compared with those of mice treated with rotenone alone (Supplementary Fig. 5), suggesting that PLX3397 might prefer to target/eliminate M1-trended microglia in neuroinflammatory or pathological conditions. Thus, we believe that the equal potency of PLX3397 and minocycline in dampening M1 microglial activation by microglial depletion and inhibition, respectively, might be one of the potential reasons for similar neuroprotective effects of these two compounds.

\section{Conclusions}

Our results reveal an important role of microglial activation in rotenone-induced cognitive deficits in mice through astroglial activation, neuroinflammation, oxidative stress, and apoptosis. Our study adds to strong experimental evidence for the connection between microglial activation and cognitive decline in PD and provides a new therapeutic target for the treatment of the nonmotor symptoms in patients in the future.

\section{Supplementary Information}

The online version contains supplementary material available at https://doi. org/10.1186/s12974-020-02065-z.

\footnotetext{
Additional file 1 Supplementary Fig 1. Rotenone dose-dependently reduces the expression of PSD-95 in CA1, CA2 and CA3 regions of mice. Quantitative analysis of PSD95 immunostaining density in CA1 (A), CA2 $(B)$ and $C A 3(C)$ regions of mice. ${ }^{* *} p<0.01$. Supplementary Fig 2 . The effects of PLX3397 and minocycline on microglial number and activation, respectively. (A) Mice were administered with $\mathrm{PLX3397}$ (40 mg/kg/day) by gavage for 1 week and the representative images of Iba- 1 immunostaining were shown. (B, C) Quantitative analysis of $\mathrm{Iba}^{-1^{+}}$cell number. $\mathrm{n}$ = 3. (D) The representative images of Iba- 1 immunostaining in rotenonetreated mice with or without minocycline were shown. $(E, F)$ Quantitative analysis of Iba-1 immunostaining density. $n=5 .{ }^{*} p<0.01$; Scale bar $=$ $50 \mu \mathrm{m}$. Supplementary Fig 3. PLX3397 and minocycline attenuate rotenone-induced reduction of PSD95 in CA1, CA2 and CA3 regions of mice. Quantitative analysis of PSD95 immunostaining density in CA1 (A), CA2 $(B)$ and $C A 3(C)$ regions of mice. ${ }^{* *} p<0.01$. Supplementary Fig 4. PLX3397 and minocycline attenuate rotenone-induced neuronal damage in mice. The representative images (40X) of PSD95 immunostaining in rotenone-treated mice with or without PLX3397 and minocycline were shown. $n=5-6$; Scale bar $=100 \mu \mathrm{m}$. Supplementary Fig 5. The effects of $\mathrm{PLX} 3397$ and minocycline on expession of iNOS and Arg-1 in the midbrain of rotenone-treated mice. (A) The expression levels of iNOS and arginase-1 (Arg-1) were detected in the midbrain of mice treated with rotenone with or without PLX3397 and minocycline by using Western blot and the representative blots were shown. (B) The blots was quantified. $n=4 ;{ }^{*} p<0.05,{ }^{* *} p<0.01$.
} 


\section{Abbreviations}

AD: Alzheimer's disease; CSF1R: Colony-stimulating factor 1 receptor; GSH: Glutathione; IL-1 $\beta$ : Interleukin-1 $\beta$; MDA: Malondialdehyde; MWM: Morris water maze; MPTP: 1-Methyl-4-phenyl-1,2,3,6-tetrahydropyridine; NOR: Novel objective recognition; PD: Parkinson's disease; PSD-95: Postsynaptic density protein; ROS: Reactive oxygen species; TNFa: Tumor necrosis factor a

\section{Acknowledgements}

Not applicable.

\section{Authors' contributions}

D.Z performed the experiments. S.L and L.H guided the experiments and gave critical comments for the research. L.H wrote the original draft and analyzed data. L.J, Z.R, B.P, and X.Z helped to perform the experiments. J.H gave critical comments for the research. J.Z gave critical comments and provided reagents. Q.W. designed the research and edited the manuscript. The authors read and approved the final manuscript.

\section{Funding}

This work was supported by the National Natural Science Foundation of China (81973087), NSFC-Liaoning Province United Foundation of China (U1908208), Liaoning Provincial Natural Science Foundation of China (2019MS-077; 2020-MS-264; 2019-MS-088), LiaoNing Revitalization Talents Program (XLYC1907026; XLYC1808031), National Major Scientific and Technological Special Project for "Significant New Drugs Development" (2019zx09301102) and technology platform project of the Educational Department of Liaoning Province-evaluation and transformation of traditional Chinese and Western medicine in critical disease.

\section{Availability of data and materials}

All data generated or analyzed during this study are included in this published article [and its supplementary information files].

\section{Ethics approval and consent to participate}

All animal procedures and their care were carried out in accordance the National Institute of Health Guide for the Care and Use of Laboratory Animals and were approved by the Institutional Animal Care and Use Committee of Dalian Medical University.

\section{Consent for publication}

Not applicable.

\section{Competing interests}

The authors declare that they have no competing interests.

\section{Author details}

${ }^{1}$ School of Public Health, Dalian Medical University, Dalian 116044, China. ${ }^{2}$ National-Local Joint Engineering Research Center for Drug-Research and Development (R\&D) of Neurodegenerative Diseases, Dalian Medical University, No. 9 W. Lvshun South Road, Dalian 116044, China. ${ }^{3}$ Neurobiology Laboratory, National Institute of Environmental Health Sciences, National Institutes of Health, Research Triangle Park, Durham, North Carolina, USA

\section{Received: 6 September 2020 Accepted: 16 December 2020}

Published online: 05 January 2021

\section{References}

1. Hou L, Li Q, Jiang L, Qiu H, Geng C, Hong JS, Li H, Wang Q. Hypertension and diagnosis of Parkinson's disease: a meta-analysis of cohort studies. Front Neurol. 2018:9:162

2. Braak H, Del Tredici K, Rub U, de Vos RA, Jansen Steur EN, Braak E. Staging of brain pathology related to sporadic Parkinson's disease. Neurobiol Aging. 2003;24:197-211.

3. Marinus J, Zhu K, Marras C, Aarsland D, van Hilten JJ. Risk factors for nonmotor symptoms in Parkinson's disease. Lancet Neurol. 2018;17:559-68.

4. Lawson RA, Yarnall AJ, Johnston F, Duncan GW, Khoo TK, Collerton D, Taylor JP, Burn DJ. Cognitive impairment in Parkinson's disease: impact on quality of life of carers. Int J Geriatr Psychiatry. 2017;32:1362-70.

5. Lawson RA, Yarnall AJ, Duncan GW, Khoo TK, Breen DP, Barker RA, Collerton D, Taylor JP, Burn DJ. Severity of mild cognitive impairment in early
Parkinson's disease contributes to poorer quality of life. Parkinsonism Relat Disord. 2014:20:1071-5.

6. Lecours C, Bordeleau M, Cantin L, Parent M, Paolo TD, Tremblay ME. Microglial implication in Parkinson's disease: loss of beneficial physiological roles or gain of inflammatory functions? Front Cell Neurosci. 2018;12:282.

7. Imamura K, Hishikawa N, Sawada M, Nagatsu T, Yoshida M, Hashizume Y. Distribution of major histocompatibility complex class II-positive microglia and cytokine profile of Parkinson's disease brains. Acta Neuropathol. 2003; 106:518-26.

8. Femminella GD, Ninan S, Atkinson R, Fan Z, Brooks DJ, Edison P. Does microglial activation influence hippocampal volume and neuronal function in Alzheimer's disease and Parkinson's disease dementia? J Alzheimers Dis. 2016:51:1275-89.

9. Menza M, Dobkin RD, Marin H, Mark MH, Gara M, Bienfait K, Dicke A, Kusnekov A. The role of inflammatory cytokines in cognition and other nonmotor symptoms of Parkinson's disease. Psychosomatics. 2010;51:474-9.

10. Hamelin L, Lagarde J, Dorothee G, Potier MC, Corlier F, Kuhnast B, Caille F, Dubois B, Fillon L, Chupin M, et al. Distinct dynamic profiles of microglial activation are associated with progression of Alzheimer's disease. Brain. 2018;141:1855-70

11. Liddelow SA, Guttenplan KA, Clarke LE, Bennett FC, Bohlen CJ, Schirmer L, Bennett ML, Munch AE, Chung WS, Peterson TC, et al. Neurotoxic reactive astrocytes are induced by activated microglia. Nature. 2017;541:481-7.

12. Santello M, Toni N, Volterra A. Astrocyte function from information processing to cognition and cognitive impairment. Nat Neurosci. 2019;22: 154-66.

13. Zhang HY, Wang Y, He Y, Wang T, Huang XH, Zhao CM, Zhang L, Li SW, Wang C, Qu YN, Jiang XX. A1 astrocytes contribute to murine depressionlike behavior and cognitive dysfunction, which can be alleviated by IL-10 or fluorocitrate treatment. J Neuroinflammation. 2020;17:200.

14. Khatri DK, Juvekar AR. Neuroprotective effect of curcumin as evinced by abrogation of rotenone-induced motor deficits, oxidative and mitochondrial dysfunctions in mouse model of Parkinson's disease. Pharmacol Biochem Behav. 2016;150-151:39-47.

15. Gokul K. Muralidhara: Oral supplements of aqueous extract of tomato seeds alleviate motor abnormality, oxidative impairments and neurotoxicity induced by rotenone in mice: relevance to Parkinson's disease. Neurochem Res. 2014;39:1382-94.

16. Yang X, Ren H, Wood K, Li M, Qiu S, Shi FD, Ma C, Liu Q. Depletion of microglia augments the dopaminergic neurotoxicity of MPTP. FASEB J. 2018 ; 32:3336-45.

17. Elmore MR, Najafi AR, Koike MA, Dagher NN, Spangenberg EE, Rice RA, Kitazawa M, Matusow B, Nguyen H, West BL, Green KN. Colonystimulating factor 1 receptor signaling is necessary for microglia viability, unmasking a microglia progenitor cell in the adult brain Neuron. 2014;82:380-97.

18. de Queiroz AIG, Chaves Filho AJM, Araujo TDS, Lima CNC, Machado MJS, Carvalho AF, Vasconcelos SMM, de Lucena DF, Quevedo J, Macedo D. Antimanic activity of minocycline in a GBR12909-induced model of mania in mice: possible role of antioxidant and neurotrophic mechanisms. J Affect Disord. 2018;225:40-51.

19. Hou L, Sun F, Huang R, Sun W, Zhang D, Wang Q. Inhibition of NADPH oxidase by apocynin prevents learning and memory deficits in a mouse Parkinson's disease model. Redox Biol. 2019;22:101134.

20. Hou L, Sun F, Sun W, Zhang L, Wang Q. Lesion of the locus coeruleus damages learning and memory performance in Paraquat and Manebinduced mouse Parkinson's disease model. Neuroscience. 2019;419:129-40.

21. Mu RH, Tan YZ, Fu LL, Nazmul Islam M, Hu M, Hong H, Tang SS. 1Methylnicotinamide attenuates lipopolysaccharide-induced cognitive deficits via targeting neuroinflammation and neuronal apoptosis. Int Immunopharmacol. 2019;77:105918.

22. Shahidi S, AsI SS, Komaki A, Hashemi-Firouzi N. The effect of chronic stimulation of serotonin receptor type 7 on recognition, passive avoidance memory, hippocampal long-term potentiation, and neuronal apoptosis in the amyloid beta protein treated rat. Psychopharmacology (Berl). 2018;235: $1513-25$.

23. Wang Q, Oyarzabal EA, Song S, Wilson B, Santos JH, Hong JS. Locus coeruleus neurons are most sensitive to chronic neuroinflammationinduced neurodegeneration. Brain Behav Immun. 2020;87:359-68.

24. Song S, Jiang L, Oyarzabal EA, Wilson B, Li Z, Shih YI, Wang Q, Hong JS. Loss of brain norepinephrine elicits neuroinflammation-mediated oxidative injury 
and selective caudo-rostral neurodegeneration. Mol Neurobiol. 2019;56: 2653-69.

25. Cohen JW, Louneva N, Han LY, Hodes GE, Wilson RS, Bennett DA, Lucki I, Arnold SE. Chronic corticosterone exposure alters postsynaptic protein levels of PSD-95, NR1, and synaptopodin in the mouse brain. Synapse. 2011; 65:763-70.

26. Bruinenberg VM, van Vliet D, Attali A, de Wilde MC, Kuhn M, van Spronsen FJ, van der Zee EA. A specific nutrient combination attenuates the reduced expression of PSD-95 in the proximal dendrites of hippocampal cell body layers in a mouse model of phenylketonuria. Nutrients. 2016;8:185.

27. Wang Q, Sun G, Gao C, Feng L, Zhang Y, Hao J, Zuo E, Zhang C, Li S, Piao F. Bone marrow mesenchymal stem cells attenuate 2,5-hexanedione-induced neuronal apoptosis through a NGF/AKT-dependent pathway. Sci Rep. 2016; 6:34715.

28. Hou L, Yang J, Li S, Huang R, Zhang D, Zhao J, Wang Q. Glibenclamide attenuates 2,5-hexanedione-induced neurotoxicity in the spinal cord of rats through mitigation of NLRP3 inflammasome activation, neuroinflammation and oxidative stress. Toxicol Lett. 2020;331:152-8.

29. Zhao Z, Wang Y, Zhou R, Li Y, Gao Y, Tu D, Wilson B, Song S, Feng J, Hong JS, Yakel JL. A novel role of NLRP3-generated IL-1 beta in the acute-chronic transition of peripheral lipopolysaccharide-elicited neuroinflammation: implications for sepsis-associated neurodegeneration. J Neuroinflammation. 2020;17:64.

30. Hou L, Huang R, Sun F, Zhang L, Wang Q. NADPH oxidase regulates paraquat and maneb-induced dopaminergic neurodegeneration through ferroptosis. Toxicology. 2019;417:64-73.

31. Hanganu A, Bedetti C, Degroot C, Mejia-Constain B, Lafontaine AL, Soland V, Chouinard S, Bruneau MA, Mellah S, Belleville S, Monchi O. Mild cognitive impairment is linked with faster rate of cortical thinning in patients with Parkinson's disease longitudinally. Brain. 2014;137:1120-9.

32. Gratwicke J, Jahanshahi M, Foltynie T. Parkinson's disease dementia: a neural networks perspective. Brain. 2015;138:1454-76.

33. Irwin DJ, Lee VM, Trojanowski JQ. Parkinson's disease dementia: convergence of alpha-synuclein, tau and amyloid-beta pathologies. Nat Rev Neurosci. 2013;14:626-36.

34. Kim HS, Suh YH. Minocycline and neurodegenerative diseases. Behav Brain Res. 2009;196:168-79.

35. Okouchi M, Ekshyyan O, Maracine M, Aw TY. Neuronal apoptosis in neurodegeneration. Antioxid Redox Signal. 2007;9:1059-96.

36. Jonas EA, Porter GA, Alavian KN. BCl-xL in neuroprotection and plasticity. Front Physiol. 2014;5:355.

37. Wang Q, Qian L, Chen SH, Chu CH, Wilson B, Oyarzabal E, Ali S, Robinson B, Rao D, Hong JS. Post-treatment with an ultra-low dose of NADPH oxidase inhibitor diphenyleneiodonium attenuates disease progression in multiple Parkinson's disease models. Brain. 2015;138:1247-62.

38. Pfeiffer RF. Non-motor symptoms in Parkinson's disease. Parkinsonism Relat Disord. 2016;22(Suppl 1):S119-22.

39. Aarsland D, Beyer MK, Kurz MW. Dementia in Parkinson's disease. Curr Opin Neurol. 2008;21:676-82.

40. Yu RL, Wu RM, Tai CH, Lin CH, Cheng TW, Hua MS. Neuropsychological profile in patients with early stage of Parkinson's disease in Taiwan. Parkinsonism Relat Disord. 2012;18:1067-72.

41. Hall H, Reyes S, Landeck N, Bye C, Leanza G, Double K, Thompson L, Halliday G, Kirik D. Hippocampal Lewy pathology and cholinergic dysfunction are associated with dementia in Parkinson's disease. Brain. 2014:137:2493-508.

42. Haga H, Matsuo K, Yabuki Y, Zhang C, Han F, Fukunaga K. Enhancement of ATP production ameliorates motor and cognitive impairments in a mouse model of MPTP-induced Parkinson's disease. Neurochem Int. 2019;129:104492.

43. Zhang X, Bai L, Zhang S, Zhou X, Li Y, Bai J. Trx-1 ameliorates learning and memory deficits in MPTP-induced Parkinson's disease model in mice. Free Radic Biol Med. 2018;124:380-7.

44. Fifel K, Dkhissi-Benyahya O, Cooper HM. Lack of long-term changes in circadian, locomotor, and cognitive functions in acute and chronic MPTP (1methyl-4-phenyl-1,2,3,6-tetrahydropyridine) mouse models of Parkinson's disease. Chronobiol Int. 2013;30:741-55.

45. Wang Q, Chu CH, Qian L, Chen SH, Wilson B, Oyarzabal E, Jiang L, Ali $S$, Robinson B, Kim HC, Hong JS. Substance P exacerbates dopaminergic neurodegeneration through neurokinin-1 receptor-independent activation of microglial NADPH oxidase. J Neurosci. 2014;34:12490-503.

46. Wang Q, Shin EJ, Nguyen XK, Li Q, Bach JH, Bing G, Kim WK, Kim HC, Hong JS. Endogenous dynorphin protects against neurotoxin-elicited nigrostriatal dopaminergic neuron damage and motor deficits in mice. J Neuroinflammation. 2012;9:124

47. Alabi AO, Ajayi AM, Ben-Azu B, Bakre AG, Umukoro S. Methyl jasmonate abrogates rotenone-induced parkinsonian-like symptoms through inhibition of oxidative stress, release of pro-inflammatory cytokines, and down-regulation of immnopositive cells of NF-kappaB and alphasynuclein expressions in mice. Neurotoxicology. 2019;74:172-83.

48. Jia F, Song N, Zhao C, Xie J, Jiang H. Unexpected improvements of spatial learning and memory abilities in chronic rotenone intoxicated mice. PLoS One. 2014;9:e91641.

49. Chen PZ, He WJ, Zhu ZR, GJ E, Xu G, Chen DW, Gao YQ. Adenosine A2A receptor involves in neuroinflammation-mediated cognitive decline through activating microglia under acute hypobaric hypoxia. Behav Brain Res. 2018; 347:99-107.

50. Jackson L, Dumanli S, Johnson MH, Fagan SC, Ergul A. Microglia knockdown reduces inflammation and preserves cognition in diabetic animals after experimental stroke. J Neuroinflammation. 2020;17:137.

51. Rosenblat JD, Brietzke E, Mansur RB, Maruschak NA, Lee Y, McIntyre RS. Inflammation as a neurobiological substrate of cognitive impairment in bipolar disorder: evidence, pathophysiology and treatment implications. J Affect Disord. 2015;188:149-59.

52. Czirr E, Castello NA, Mosher KI, Castellano JM, Hinkson IV, Lucin KM, BaezaRaja B, Ryu JK, Li L, Farina SN, et al. Microglial complement receptor 3 regulates brain Abeta levels through secreted proteolytic activity. J Exp Med. 2017;214:1081-92.

53. Cope EC, LaMarca EA, Monari PK, Olson LB, Martinez S, Zych AD, Katchur NJ, Gould E. Microglia play an active role in obesity-associated cognitive decline. J Neurosci. 2018;38:8889-904.

54. Dagher NN, Najafi AR, Kayala KM, Elmore MR, White TE, Medeiros R, West BL, Green KN. Colony-stimulating factor 1 receptor inhibition prevents microglial plaque association and improves cognition in 3xTg-AD mice. J Neuroinflammation. 2015;12:139.

55. Shi E, Shi K, Qiu S, Sheth KN, Lawton MT, Ducruet AF. Chronic inflammation, cognitive impairment, and distal brain region alteration following intracerebral hemorrhage. FASEB J. 2019;33:9616-26.

56. Feng X, Jopson TD, Paladini MS, Liu S, West BL, Gupta N, Rosi S. Colony-stimulating factor 1 receptor blockade prevents fractionated whole-brain irradiation-induced memory deficits. J Neuroinflammation. 2016;13:215.

57. Hou L, Zhang L, Hong JS, Zhang D, Zhao J, Wang Q. Nicotinamide adenine dinucleotide phosphate oxidase and neurodegenerative diseases: mechanisms and therapy. Antioxid Redox Signal. 2020:33:374-93.

58. Yin $P$, Wang $X$, Wang $S$, Wei $Y$, Feng J, Zhu M. Maresin 1 Improves cognitive decline and ameliorates inflammation in a mouse model of Alzheimer's disease. Front Cell Neurosci. 2019;13:466.

59. Tian J, Tai Y, Shi M, Zhao C, Xu W, Ge X, Zhu G. Atorvastatin relieves cognitive disorder after sepsis through reverting inflammatory cytokines, oxidative stress, and neuronal apoptosis in hippocampus. Cell Mol Neurobiol. 2020:40:521-30.

60. Burke NN, Kerr DM, Moriarty O, Finn DP, Roche M. Minocycline modulates neuropathic pain behaviour and cortical M1-M2 microglial gene expression in a rat model of depression. Brain Behav Immun. 2014;42:147-56.

61. Xu N, Tang XH, Pan W, Xie ZM, Zhang GF, Ji MH, Yang JJ, Zhou MT, Zhou $Z Q$. Spared nerve injury increases the expression of microglia M1 markers in the prefrontal cortex of rats and provokes depression-like behaviors. Front Neurosci. 2017;11:209.

62. Dai J, Ding Z, Zhang J, Xu W, Guo Q, Zou W, Xiong Y, Weng Y, Yang Y, Chen $\mathrm{S}$, et al. Minocycline relieves depressive-like behaviors in rats with bone cancer pain by inhibiting microglia activation in hippocampus. Anesth Analg. 2019;129:1733-41.

63. Liang YJ, Feng SY, Qi YP, Li K, Jin ZR, Jing HB, Liu LY, Cai J, Xing GG, Fu KY Contribution of microglial reaction to increased nociceptive responses in high-fat-diet (HFD)-induced obesity in male mice. Brain Behav Immun. 2019; 80:777-92.

\section{Publisher's Note}

Springer Nature remains neutral with regard to jurisdictional claims in published maps and institutional affiliations. 